\title{
Human Fetal Antibody-Dependent Cellular Cytotoxicity to Herpes Simplex Virus-Infected Cells
}

\author{
DANIEL V. LANDERS, JANIS P. SMITH, CHERYL K. WALKER, TERRY MILAM. \\ LISA SANCHEZ-PESCADOR, AND STEVE KOHL

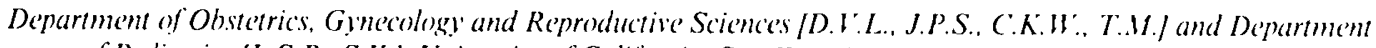 \\ of Pediatrics /L.S-P.. S.K.J. University of California, San Francisco, San Francisco General Hospital. \\ San Francisco, California 94110
}

\begin{abstract}
Human fetal antibody-dependent cellular cytotoxicity (ADCC) has not been reported previously. Most investigations have failed to document any cytolytic activity among fetal lymphocytes. The purpose of this study was to investigate $\mathrm{ADCC}$ activity in the human fetus and identify and characterize the effector cell populations in the fetus. Fetal spleen cells were separated into single-cell suspensions and assayed with ${ }^{51} \mathrm{Cr}$-labeled herpes simplex 1 -infected Chang liver target cells. Significant ADCC activity was detected in 19 of $26(73 \%)$ of freshly assayed fetal spleen cell preparations from fetuses of 17-24 wk gestational age. This activity, however, was significantly less than concurrently run adult peripheral blood mononuclear cells. After plastic adherence the fetal spleen ADCC activity from nonadherent cells was not significantly different from whole spleen preparations. Surprisingly, ADCC activity in nonadherent fetal cells dropped significantly after exposure to latex beads, an effect not seen in nonadherent adult lymphocytes. Thus, either fetal monocyte-derived (macrophages) fetal spleen cells do not efficiently adhere to plastic or a unique nonadherent population of latex-sensitive immunocytes is capable of mediating ADCC activity in the fetus. We suspect the former conclusion to be the more plausible; however, fluorescence-activated cell sorter staining of fetal cells was not sufficient to confirm these suspensions by fluorescence-activated cell sorter analysis. (Pediatr Res 35: 289-292, 1994)
\end{abstract}

\section{Abbreviations}

ADCC, antibody-dependent cellular cytotoxicity

FACS, fluorescence-activated cell sorter

FSMC, fetal spleen mononuclear cell

HBSS, Hanks' balanced salt solution

HSV, herpes simplex virus

PBMC, peripheral blood mononuclear cell

ADCC is a mechanism whereby leukocyte effector cells expressing the receptor for Ig destroy antibody-sensitive target cells. ADCC in general, and specifically against viral infected cells, has

Received July 20, 1993; accepted October 22, 1993.

Correspondence: Daniel V. Landers, M.D., Dept. OB-GYN, Rm. 6D23, San Francisco General Hospital, 1001 Potrero Ave., San Francisco. CA 94110.

Supported in part by NIH IPO1-HD24640, HD!3021, and AI32384. D.V.L. was the recipient of an NIH (NICHD) Physician Scientist Award (K1 I-HD00750), an American Gynecological and Obstetrical Society Physician Scientist Award (Kennedy-Danreuther), and is currently a Pediatric AIDS Foundation (PAF) American Foundation for AIDS Research (AMFAR) Scholar. not been clearly demonstrated to be mediated by human fetal cells. Cells from fetal spleen and peripheral fetal blood may express cell surface antigens characteristic of mature immunocytes, but limited functional capacity has been identified (1-5). In particular, there is very little demonstrated capacity for cellmediated cytotoxicity among fetal immunocytes in midtrimester. Most information has been derived from umbilical cord blood samples after delivery. Cell-mediated lympholysis (CML) has been described in peripheral blood of human fetuses of 18-21 wk gestation, but no such activity was detected in fetal thymus or spleen cells (2-4). No studies have been published that specifically address the issue of ADCC during fetal life.

The active transport of maternal IgG across the human placenta is presumed to play an important role in fetal immune protection: ADCC activity could be an important defense in situations in which the fetus is exposed to foreign antigens, such as HSV, that infect cells. ADCC is known to play an important role in the immune response to HSV infection in neonates after delivery (5). The present study was designed to determine the extent of fetal ADCC activity against HSV-infected cells and the effector cell populations responsible for such activity.

\section{MATERIALS AND METHODS}

Fetal spleen cells. Whole spleens were obtained from 23 normal human fetuses after elective pregnancy termination between 17 and 24 wk gestational age. Spleens were immediately minced and passed through a fine wire-mesh filter, washed in HBSS and subjected to Ficoll-Hypaque differential centrifugation. The mononuclear cell layer was then removed, washed three times in HBSS, and resuspended in minimum essential medium with Earle's salts containing $0.05 \mathrm{U} / \mathrm{L}$ penicillin, $50 \mathrm{~g} / \mathrm{L}$ streptomycin, $2 \mathrm{mM}$ glutamine, and $10 \%$ heat-inactivated fetal bovine serum (Hyclone Laboratories, Logan, UT) for use as effector cells.

Human peripheral blood lymphocytes. Venous blood samples were obtained aseptically from adult volunteer donors and collected in sodium-citrated Vacutainer tubes (Becton-Dickinson, Rutherford, NJ) and immediately subjected to Ficoll-Hypaque differential centrifugation. The mononuclear cell layer was removed, washed three times in HBSS, and resuspended in minimum essential medium with Earle's salts containing $0.05 \mathrm{U} / \mathrm{L}$ penicillin, $50 \mathrm{~g} / \mathrm{L}$ streptomycin, $2 \mathrm{mM}$ glutamine, and $10 \%$ heatinactivated fetal bovine serum for use as effector cell controls.

Isolation of nonadherent populations. Mononuclear cell suspensions were obtained as described above. Cells were adhered in six-well 96.2- $\mathrm{mm}^{2}$ plates (Linbro, ICN Flow, Costa Mesa, CA). Approximately $5 \times 10^{6} \mathrm{FSMC}$ or adult PBMC were plated in 5 $\mathrm{mL} \mathrm{HBSS}$ and incubated for 1 to $2 \mathrm{~h}$ at $37^{\circ} \mathrm{C}$ in $95 \%$ air, $5 \%$ $\mathrm{CO}_{2}$. After incubation, the nonadherent population was removed and the plate washed three times with HBSS. The cells were 
pelleted and resuspended in minimum essential medium. Cell counts were determined and viability verified by trypan blue exclusion. ADCC assays were performed as described below.

Addition of uniform latex particles. For all assays involving the use of uniform latex particles, $1.1-\mu \mathrm{m}$ diameter (Dow Chemical Co., Indianapolis, IN), the individual cell suspensions were obtained and treated as described above. The target cells $\left(10^{3}\right.$ cells/ well), the effector cells (whole cell, nonadherent cell, and adherent cell suspensions at $5 \times 10^{4}$ cell/well $)$, and latex particles $(10$ $\mu \mathrm{L}$ ) were added to the assay plate and incubated for $1 \mathrm{~h}$ at $37^{\circ} \mathrm{C}$ in $95 \%$ air, $5 \% \mathrm{CO}_{2}$. Control plates (effectors, targets, and $10 \mu \mathrm{L}$ media) were also plated and incubated for $1 \mathrm{~h}$ at $37^{\circ} \mathrm{C}$. After the 1-h incubation, HSV 1-positive sera, HSV 1-negative sera, or media were added to appropriate wells. Plates were then incubated for $18 \mathrm{~h}\left(37^{\circ} \mathrm{C}, 5 \% \mathrm{CO}_{2}\right)$ and harvested as described.

Virus and target cells. The HE strain of HSV 1 was originally isolated in the laboratory of Dr. A. J. Nahimias (Emory University, Atlanta, GA). It was propagated in human Chang liver cells using minimum essential medium with Earle's salts containing $0.05 \mathrm{U} / \mathrm{L}$ penicillin, $50 \mathrm{~g} / \mathrm{L}$ streptomycin, $2 \mathrm{mM}$ glutamine, and $10 \%$ heat-inactivated fetal bovine serum.

Sera. Human blood was obtained aseptically from volunteer donors. After the blood clotted overnight at $4^{\circ} \mathrm{C}$, serum was removed, centrifuged at $200 \times g$ for $10 \mathrm{~min}$ at room temperature, and inactivated at $50^{\circ} \mathrm{C}$ for $30 \mathrm{~min}$. All sera were characterized as HSV antibody-positive or -negative by ELISA, Western blot, neutralization, and ADCC assay with known human standards. The HSV-positive sample was characterized as being HSV 1+/ HSV2- in the laboratory of Dr. Ann Arvin (Department of Pediatrics, Stanford University School of Medicine, Palo Alto, CA) with an HSV 2 specific IgG ELISA.

$A D C C$ assay. As previously described in detail, ADCC was determined with HE strain HSV 1 -infected ${ }^{51} \mathrm{Cr}$-labeled Chang liver target cells approximately $24 \mathrm{~h}$ after infection (6-8). Effector cells were added to target cells to a final volume of $0.2 \mathrm{~mL}$ in 96-well round-bottom microtiter plates (Corning Glass Works, Corning, NY). Fetal spleen cells were used at an optimal effectorto-target cell ratio of $50: 1$ as determined by titration curve. Optimal antibody dilution was determined to be $100: 1$ by antibody titration curve. Effector cells consisted of human fetal spleen cells or adult peripheral blood cells prepared as described above. Serum known to be positive or negative for anti-HSV antibody was diluted in media and added to wells to achieve a final dilution of 1:100. Assays were harvested after an 18-h incubation at $37^{\circ} \mathrm{C}$ in $5 \% \mathrm{CO}_{2}$-enriched air by aspirating $100 \mu \mathrm{L}$ from the top of each well without disturbing the cell pellet. To each well, $100 \mu \mathrm{L}$ of $\mathrm{NaOH}$ was added and the total remaining volume aspirated into a separate container. Each sample was counted in a Beckman 4000 gamma counter for 1 min (Beckman Instruments, Fullerton, $\mathrm{CA}) .{ }^{\mathrm{Si}} \mathrm{Cr}$ release was calculated according to the following formula:

$$
\%^{\text {sI }} \mathrm{Cr} \text { release }=\frac{2 \mathrm{~A}}{\mathrm{~A}+\mathrm{B}} \times 100
$$

where $\mathrm{A}=\mathrm{cpm}$ in top $100 \mu \mathrm{L}$ and $\mathrm{B}=\mathrm{cpm}$ in the pellet to which $\mathrm{NaOH}$ was added. ADCC was calculated as follows:

$$
\begin{aligned}
& \% \text { ADCC }= \\
& \left\{\left[\left(\%^{51} \mathrm{Cr} \text { release of target cells }+ \text { effector cells }+ \text { immune sera }\right)-\right.\right. \\
& \left.\left(\%^{51} \mathrm{Cr} \text { release of target cells }+ \text { effector cells }+ \text { nonimmune sera }\right)\right] \\
& +\left(100-\%^{\text {si }} \mathrm{Cr}\right. \text { release of target cells } \\
& + \text { effector cells }+ \text { nonimmune sera })\} \times 100
\end{aligned}
$$

In this assay system, more than $10 \% \mathrm{ADCC}$ is significant $(7,8)$.

Immunofluorescence staining of cell surfaces. Fetal spleen cell preparations and adult PBMC were prepared as described. After isolation, cells were suspended in staining media (RPMI $1640+$
$3 \%$ FCS $=10 \mathrm{mM} N$-2-hydroxyethylpiperazine- $N^{\prime}$-2-ethanesulfonic acid $+0.1 \%$ sodium azide). Cells were counted and viability confirmed by trypan exclusion. FMSC or PBMC were incubated with the manufacturer's suggested concentration of fluorochrome-conjugated anti-CD $\mathrm{CD}_{3}$, Leu-M1, anti-CD $\mathrm{CD}_{16}$, or anti-CD $\mathrm{CD}_{56}$ (NKH-1) MAb (Becton Dickinson, Palo Alto, CA). All incubations were performed for $20 \mathrm{~min}$ at $2-8^{\circ} \mathrm{C}$ in the dark. After incubation, cells were washed three times with cold staining media and fixed in $2 \%$ formaldehyde. Stained cells were kept refrigerated and protected from light until analyzed.

FACS analysis. Single- and dual-color immunocytometry was performed on the FACS 440 (Becton Dickinson). Ten thousand events were collected and analyzed using FACS/DESK software (version 1.9).

Statistical analysis. Data are expressed as the mean \pm SD. Differences were determined using $t$ test for unpaired samples for continuous variables and $\chi^{2}$ or Fisher's exact test for discrete variables.

Ethical considerations. All specimens were obtained after appropriate informed consent and within the guidelines set forth by the University of California, San Francisco Committee on Human Research (IRB). This research did not fall under the moratorium of the Department of Health and Human Services because no therapeutic transplantation of fetal tissue was involved.

\section{RESULTS}

FSMC versus adult PBMC. ADCC activity in this assay system was considered significant if it was more than $10 \%$ above baseline activity with control (antibody-negative) serum. Significant ADCC activity was detected in 19 of $26(73 \%)$ FSMC preparations of 17-24 wk gestation. ADCC data comparing the means of 19 separate fetal spleen cell preparations with significant activity and PBMC preparations is shown in Figure 1. The mean ADCC activity detected in fetal spleen cells was $26.6 \pm 12.9 \%$. This activity was significantly less $(p<0.01)$ than the $39.0 \pm$ $8.6 \%$ activity found in concurrently run human adult PBMC. The presence of ADCC activity in fetal spleen cells did not correlate with gestational age.

Nonadherent fetal spleen cells versus whole FSMC. As shown in Figure 2, ADCC activity in nonadherent fetal spleen cells $(20.3 \pm 7.6 \%)$ was not significantly different from whole spleen preparations $(20.7 \pm 4.7 \%, p=0.08)$. Activity in the adherent population (not shown) could not be assessed directly because of poor viable cell recovery.

Nonadherent fetal spleen cells versus adult nonadherent PBMC after exposure to latex beads. Latex has been shown to be a specific inhibitor of macrophage ADCC in this system (8). Because adherent cells normally represent cells of the monocyte-

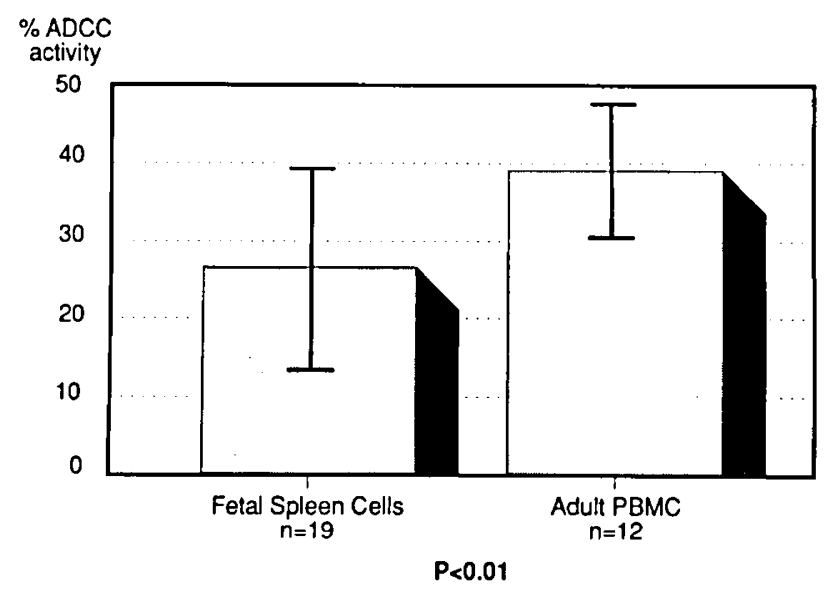

Fig. 1. ADCC activity comparing whole fetal spleen cell preparations with adult PBMC. 


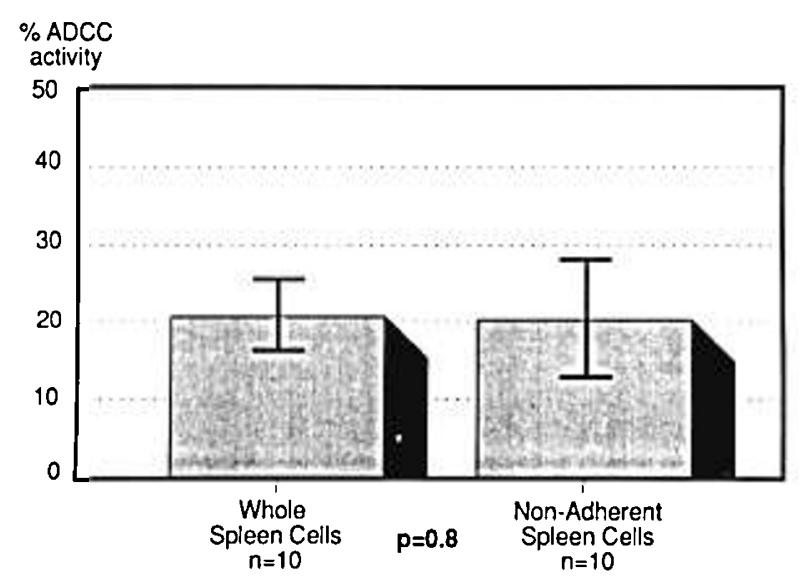

Fig. 2. ADCC activity comparing whole spleen cell populations with nonadherent preparations.

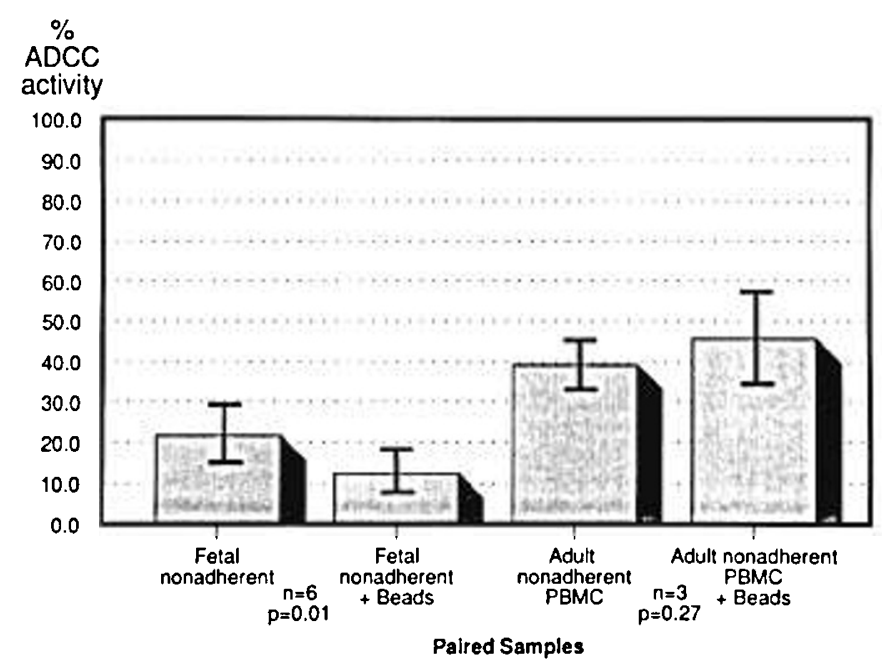

Fig. 3. ADCC activity in fetal and adult nonadherent cells before and after latex bead exposure.

macrophage lineage, latex-bead experiments were performed after adherence to confirm the absence of these cells from the population. Surprisingly, ADCC activity in nonadherent fetal spleen cells $(20.3 \pm 7.6 \%)$ dropped significantly to $12.4 \pm 4.8 \%$ ( $p<0.01$ ), $n=6$, after exposure to latex beads as shown in Figure 3. No such effect was found in nonadherent adult PBMC $(39.3 \pm 5.1 \%)$ after exposure to latex beads $(45.7 \pm 11.7 \%, p=$ 0.27 ), also shown in Figure 3 . Thus, a latex-sensitive, nonadherent cell population capable of ADCC activity was present in fetal spleen cell preparations that is not found in similarly treated adult lymphocyte populations. When whole cell populations (FSMC and PBMC) were tested before adherence and macrophage removal of adult cells, a significant drop in ADCC activity could be seen in both the FSMC and the PBMC after exposure to latex beads (Fig. 4).

$F A C S$. Among fetal cells derived from ADCC active whole spleen preparations, $36 \%(n=13)$ were $\mathrm{CD}_{3}(+), 12.4 \%(n=13)$ were $\mathrm{CD}_{16}$ (Leul1)-positive, and $8.4 \%(n=11)$ were $\mathrm{CD}_{56}$ (Leu19)-positive. Among the ADCC active nonadherent fetal spleen cell preparations, $31 \%(n=8)$ were $\mathrm{CD}_{3}(+), 6.8 \%(n=8)$ were $C_{16}(t)$, and $10.4 \%(n=8)$ were $C D_{56}(t)$. No significant differences were observed between whole spleen cell preparations and nonadherent cells. Adherent cell populations were too few in recoverable numbers for FACS staining.

\section{DISCUSSION}

Little information is available concerning immune cellular cytotoxicity in the fetus. The few published reports indicate that

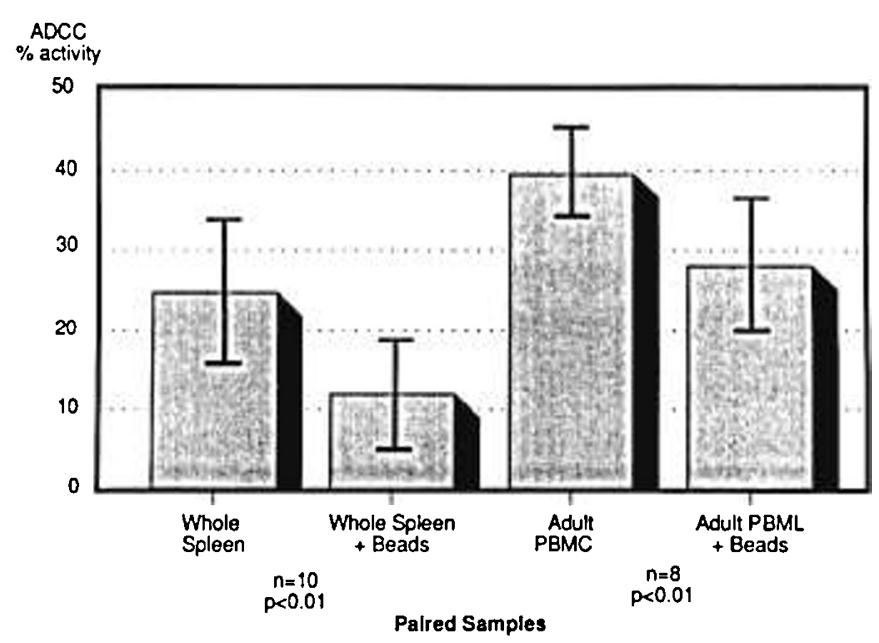

Fig. 4. ADCC activity in fetal and adult whole spleen cell preparations compared with adult PBMC before and after latex bead exposure.

although some capacity for natural killer cell cytotoxicity exists, no allogeneic or antibody-dependent cellular cytotoxicity has been demonstrated. This demonstration has been limited to a few reports on cell-mediated lympholysis (1-3). In the current study we have demonstrated the capacity of leukocytes from $73 \%$ of midtrimester fetal spleens to mediate ADCC against HSV type 1 -infected target cells sensitized by anti-HSV antibody. This finding has relevance to both the mechanisms of fetal immune protection in general and specifically against HSV infection. Because no correlation existed between the presence and level of ADCC activity and the gestational age within the 17-24 wk range of acquired specimens, the presence of ADCC activity does not seem to be associated with more advanced gestational ages within the midtrimester. However, this finding does not preclude the activity being dependent on the development or maturation of immune cells/factors because the activity may vary among fetuses within this gestational age range. The capacity for ADCC activity in the fetus may also depend on external factors, such as microbial antigenic exposure of the fetus. It is well known, for example, that certain viruses are capable of entering the fetal circulation transplacentally very early in gestation.

The passive acquisition of maternal IgG has to a large extent been credited for the immune defense against microbial invasion of the fetal compartment. The exact mechanisms by which maternal antibody provides this defense have not been described. Although the formation of antigen-antibody complexes or viral neutralization may play a role, passively acquired antibody should also be capable of mediating ADCC activity if adequate numbers of effector cells capable of ADCC are present. This may be particularly relevant to fetal protection against HSV or other viral infection where 1 st or 2 nd trimester fetal exposure to virus may be seen without subsequent signs of neonatal infection. Indeed, apparently $5 \%$ of neonatal human immunodeficiency virus is congenital (i.e., acquired in utero) (9). Because neonatal human immunodeficiency virus is not always lethal, some fetal defense mechanism must be in effect.

In the blood of adults, the effector cells responsible for ADCC to HSV-infected cells include Fc receptor-positive polymorphonuclear leukocytes, non-T cell, non-B cell lymphocytes (natural killer cells) and Fc receptor-positive monocyte-macrophages (8, 10 ). These cells have been further characterized by their plastic adherence and latex sensitivity. The two populations involved are the nonadherent, latex-resistant lymphocytes and the plastic adherent latex-sensitive macrophages (8). It has further been shown that the lymphocyte effector cells require less antibody and mediate ADCC more rapidly than monocyte-macrophage effector cells (8). Studies have revealed that ADCC activity in the human neonate may be blunted compared with the adult response. The ability of human cord blood mononuclear cells to 
mediate anti-HSV ADCC was shown to be significantly lower than that of adult leukocytes $(6,7)$. Although the neonatal ADCC response did not reach the magnitude of the adult, significant ADCC activity did occur. In one study in which a small number of adherent and nonadherent cell populations were studied separately, neither population of cells showed significantly lower ADCC than did adult cells (11). In the present study, fetal spleen cell ADCC activity was present in $73 \%$ of fetuses tested between 17 and $24 \mathrm{wk}$; however, the activity was significantly less than adult PBMC. Unfortunately, effector function of cells from adult spleen could not be obtained, precluding another control comparison.

When plastic adherent cells were removed from fetal cells, ADCC activity persisted at levels similar to whole spleen preparations. Latex beads have been shown to specifically inhibit macrophage ADCC. After exposure to latex beads, nonadherent fetal spleen cells exhibited a significant decrease in ADCC activity, unlike that response seen with adult nonadherent cells. Latex treatment did reduce the ADCC of unseparated cells from both fetuses and adults, probably because of its effect on the monocyte-macrophage population present in both groups of cells. These data suggest the presence of a nonadherent, latex-sensitive population of fetal ADCC effector cells. We conclude from these findings that fetal spleen monocyte-macrophage cells may lack the ability to efficiently adhere to plastic. This conclusion is further supported by the paucity of adherent cells recoverable after plastic adherence. An alternative, less likely, conclusion is that a unique cell population of fetal spleen cells exists characterized by latex sensitivity but not of the monocyte-macrophage lineage.

Although fetal spleen cells did not bind fluorescent-labeled $\mathrm{MAb}$ as well as adult PBMC, FACS analysis did reveal $36 \%$ $\mathrm{CD}_{3}(+)$ staining for whole fetal spleen preparations, which is consistent with the one previous report on fetal spleen cells (12). Because the absence of cells from the monocyte-macrophage cell line should be reflected in increased percentages of $\mathrm{CD}_{3}(+)$ cells in the nonadherent population, an unexpected finding was that only $31 \%$ of nonadherent fetal spleen cells were $\mathrm{CD}_{3}(+)$. Thus, either the nonadherent population contains a significant number of $\mathrm{CD}_{3}(-)$ lymphocytes capable of mediating ADCC activity as seen in adult PBMC $\left(\mathrm{CD}_{16}(+), \mathrm{CD}_{56}(+), \mathrm{CD}_{3}(-)\right.$ cells or $\mathrm{CD}_{56}$ "bright," $\mathrm{CD}_{16}(-), \mathrm{CD}_{3}(-)$ cells), or fetal cells of the monocytemacrophage line do not effectively adhere (13). Lanier et al. (13) found that in adult PBMC most $\mathrm{CD}_{56}(+)$ lymphocytes mediating non-MHC-restricted cytotoxicity against natural killer-sensitive tumor cells $(\mathrm{K} 562)$ were either $\mathrm{CD}_{3}(-) / \mathrm{CD}_{16}(+)$ or $\mathrm{CD}_{3}(+)$ / $\mathrm{CD}_{16}(-)$. The paucity of nonadherent fetal spleen cells expressing either $C D_{16}(6.8 \%)$ or $C D_{56}(10.4 \%)$ in this study further supports the hypothesis that a nonadherent population of monocytemacrophage-derived cells capable of mediating ADCC activity are present in the midtrimester human fetus. Because the fetal spleen cells had poor affinity for monocyte-specific (Leu-M1) fluorescent-labeled MAb, this hypothesis could not be confirmed definitively on the basis of FACS analysis alone.

Although Ig levels in the fetus are not as high as those of adults until the 3 rd trimester, Ig transport begins in the 2 nd to $3 \mathrm{rd} \mathrm{mo}$ of gestation (14). Along with intact ADCC effector function, this transport should allow for ADCC to be one of the defense mechanisms of the fetus. Further analysis of fetal effector cell mechanisms and response to other pathogens may clarify the role of $\mathrm{ADCC}$ in the fetus.

\section{REFERENCES}

1. Rayfield LS, Brent L, Rudeck CH 1980 Development of cell-mediated lympholysis in human foetal blood lymphocytes. Clin Exp Immunol 42:561570

2. Granberg C, Hirvonen T 1981 Cell-mediated lympholysis by fetal and neonatal lymphocytes in sheep and man. Cell Immunol 51:15-22

3. Granberg C, Hirvonen T 1980 Cell-mediated lympholysis by human neonatal lymphocytes. Clin Immunol Immunopathol 6:256-263

4. Toivanen P, Uksila J, Leino A, Lassila O, Hirvonen T, Ruuskanen O 1981 Development of mitogen responding $T$ cells and natural killer cells in the human fetus. Immunol Rev 57:89-105

5. Kohl S 1991 Role of antibody-dependent cellular cytotoxicity in defense against herpes simplex virus infection. Rev Infect Dis 13:108-114

6. Shore SL, Milgrom H, Wood P, Nahmias AJ 1977 Neonatal function of antibody-dependent cell-mediated cytotoxicity to target cells infected with herpes simplex virus. Pediatrics 59:22-28

7. Kohl S, Loo LS, Gonik B 1984 Analysis in human neonates of defective antibody-dependent cytotoxicity and natural killer cytotoxicity to herpes simplex virus-infected cells. J Infect Dis 150:14-19

8. Kohl S, Starr SE, Oleske J, Shore SL, Ashman RB, Nahmias AJ 1977 Human monocyte-macrophage mediated antibody-dependent cytotoxicity to herpes simplex virus infected cells. J Immunol 118:729-735

9. Hutto C, Arvin A, Jacobs R, Steele R. Stagno S, Lyrene R, Willett L, Powell D, Andersen R, Werthammer J, Ratcliff G, Nahmias A, Christy C, Whitley R 1987 Intrauterine herpes simplex virus infection. J Pediatr 110:97-101

10. Oleske JM, Ashman RB, Kohl S, Shore SL, Starr SE, Wood P, Nahmias AJ 1977 Human polymorphonuclear leukocytes as mediators of antibody dependent cellular cytotoxicity to herpes simplex virus-infected cells. Clin Exp Immunol 27:446-453

11. Kohl S, Shaban SS, Starr SE, Wood PA, Nahmias AJ 1978 Human neonatal and maternal monocyte macrophage and lymphocyte-mediated antibodydependent cytotoxicity to cells infected with herpes simplex. J Pediatr 93:206-210

12. DeBiagi M, Andreani M. Centis F 1985 Immune characterization of human fetal tissues with monoclonal antibodies. Prog Clin Biol Res 193:89-94

13. Lanier LL, Le AM, Civin KI, Loken MR, Phillips MR 1986 The relationship of $\mathrm{CD}_{16}$ (Leu-11) and Leu-19 (NKH-1) antigen expression on human peripheral blood NK cells and cytotoxic T lymphocytes. J Immunol 136:44804485

14. Wilson C 1990 Developmental immunology and role of host defenses in neonatal susceptibility. In: Remington JS, Klein JO (eds) Infectious Diseases of the Fetus and Newborn Infant. WB Saunders, Philadelphia, pp 25-27 